\title{
Carcinoid heart disease from primary carcinoid tumour of the ovary Haemodynamic and cine coronary angiocardiographic study after operation
}

\author{
E. Stephan and J. de Wit \\ From the Department of Internal Medicine, Baabda State Hospital, and the Laboratory of Histology, French \\ Faculty of Medicine, Beirut, Lebanon
}

Eight cases of carcinoid heart disease associated with primary ovarian carcinoid tumour have been previously reported. A case is described in which rapid relief of all symptoms followed removal of an ovarian carcinoid argentaffin tumour. A diagnostic finding was the provocation of flushing by pressure on the ovarian mass on vaginal examination. Cardiological investigations, performed two and a half months after operation, are presented. A peculiar angiocardiographic feature was the loss of trabeculations of the right ventricle.

Examples of primary carcinoid tumour of the ovary are being recognized with increasing frequency since the report of the first two cases by Stewart, Willis, and De Saram (1939) and more particularly after the classical description of the carcinoid syndrome in 1954 (Thorson et al.). Chatterjee and Heather (1968) reviewed 3I cases up to 1967. In the recent series of Haines (I97I), 6 cases out of 8 were considered primary. Primary ovarian carcinoids commonly arise from an element of a benign cystic teratoma (dermoid cyst). When no teratomatous elements are found, a diligent search is necessary to rule' out ovarian metastasis from an extrinsic source, usually the small bowel. It is not known why some carcinoids release endocrine products while others do not. Chatterjee and Heather (1968) could find features of the carcinoid syndrome in 14 cases out of 31 , and Haines (197I) in 4 cases out of 8 at the time of operation.

Carcinoid heart disease complicates primary carcinoid of the ovary only in some cases and is therefore more rare. Chatteriee and Heather (1968) reported a case and reviewed three others up to 1967 (Thorson et al., 1958; Torvik, 1960; Ellis, 1965). A fifth case with necropsy findings is that of Bancroft, O'Brien, and Tickner (1964). Since I967, 3 new cases have been reported (Ruckes and Stallkamp, 1967; Mouchet, Guivarc'h, and Voinchet, 1969; Acar et al., 1970). Three patients died without operation. At necropsy the typical endo- cardial fibrosis was found with pulmonary stenosis and tricuspid valvar disease. The 6 other patients underwent laparotomy with oophorectomy. Rapid relief of symptoms was obtained in all 6 patients.

The ovary is a unique site for primary carcinoids because endocrine products of the tumour are drained directly into the systemic venous circulation. Thus the carcinoid syndrome is likely to appear early and before any metastasis has occurred. Therefore, radical surgical cure is possible. Unlike carcinoids of the ovary, carcinoids of the small intestine have their endocrine products drained into the liver where they are metabolized. Thus the carcinoid syndrome does not occur unless metastases have been established in areas (mainly in the liver) with direct access to the systemic venous circulation.

However, long-term prognosis in primary ovarian carcinoid is uncertain. Metastases have occurred in 2 cases of Haines' series (I97I) with death $I$ and 7 years after surgical removal of the primary tumour.

\section{Case report}

A 48-year-old married woman was referred in September 1972, for an intractable heart failure with orthopnoea, ascites, and lower limb oedema of about 8 months' duration. She was treated with digoxin, $0.5 \mathrm{mg}$ per day, and diuretics. She had suffered during the previous 2 years from cough and short attacks of wheezing. At the same time there had been chronic diarrhoea with borborygmi and weight loss from 94 to $70 \mathrm{~kg}$. 
Recently, her stools had become almost liquid, with to to 15 motions per day. There was no previous history of rheumatic fever, chorea, leg phlebitis, kidney, or liver disease. She was not diabetic. She had had 7 normal pregnancies and deliveries, the last one 16 years ago. Her periods ceased at the age of 44 .

The whole body skin was red in colour, the covered parts pink, the face and dorsum of hands dark red and mildly cyanotic. The cheeks and nose were scaly with a dirty-brown colour suggestive of pellagra. Four or five small venous telangiectases were noted on the face. She had a history for the past 13 to 14 years of spells of generalized hot flushes which increased in severity and daily frequency from year to year. They used to last from 5 to 20 minutes. They were brought on by emotion, straining at stool, strong vinegar, some cough syrups, and, instantly, by any alcoholic beverage intake. The tongue was mildly sore and hyperaemic with a large dorsal depapillated area. The thyroid was not enlarged. The neck veins were much distended and strongly pulsating with systole. The right lung base was dull.

Cardiac examination revealed a diffuse praecordial lift, more pronounced in the sternal and left parasternal region, a loud parasternal pansystolic murmur which did not increase with inspiration with a faint diastolic rumble, and a soft systolic ejection murmur at the pulmonary area. Phonocardiograms confirmed these findings. The electrocardiogram showed pronounced right axis deviation and low voltage of $Q R S$ in all leads. Chest radiography showed a cardiothoracic ratio of $18.5 / 30 \mathrm{~cm}$, with right atrial and ventricular enlargement. The liver was palpable 5 fingerbreadths below the right costal margin, and systolic pulsation was felt. There was abdominal shifting dullness. The spleen was not palpable.

There was a massive pitting oedema involving the whole lower limbs and the lower part of the abdominal wall. There was no hirsutes and fat distribution was normal. Blood pressure readings were within normal limits and did not show any remarkable variations during flushing attacks.

On vaginal examination a mass was felt in the right pelvis. Palpation of this mass was followed by a flushing spell.

Routine blood examination, including urea, sugar, creatinine, alkaline and acid phosphatases, electrolytes, red and white blood cell count, haematocrit, haemoglobin, platelet count, and prothrombin time were normal. The urine contained few red cells and a trace of protein. Determination of the 24-hour excretion of 5hydroxyindole acetic acid (5-HIAA) in the urine was done three times at weekly intervals; the results were I80, 210 , and $194 \mathrm{mg}$, respectively.

Search for carcinoid tumours included chest tomography, gastrointestinal tract radiography with special attention to the small intestine, and barium enema up to the distal ileum. No abnormal findings were disclosed. Rectosigmoidoscopy up to $30 \mathrm{~cm}$ was normal. Radioisotope scans of the liver with Technetium and colloidal gold did not reveal any filling defect.

The pelvic mass was then again palpated on vaginal examination and gently squeezed. A severe flushing attack occurred. This was obtained several times again with the same manoeuvre the following days. It did not occur with manipulation of the pouch of Douglas, the uterus, and the left pelvis. Likewise, the liver, which was much enlarged and possibly infiltrated, was compressed during full inspiration and expiration. No flushing occurred.

A median laparotomy was performed in October 1972. About $2500 \mathrm{ml}$ straw-coloured ascitic fluid were aspirated. A tumour, the size of a big apple, was found in the place and site of the right ovary. It was not adherent to the surrounding tissues and was easily resected. On section, it was found to be entirely solid and firm, and as it was thought to be cancerous a total resection of the uterus with the left ovary and tube was performed. The appendix and the omentum, though of normal appearance, were also removed. Scrutiny of the colon, small intestine, pancreas, stomach, and external biliary ducts did not reveal any abnormalities. Lymph glands were not enlarged. The liver, about twice its normal size, was congested and pulsating strongly with each heart beat. No induration could be felt. Two liver biopsy specimens were taken from the right and left lobes.

\section{Pathology}

The ovarian mass, examined after fixation for 24 hours in formalin, was ovoid and well encapsulated. It measured II $\times 8 \times 6 \mathrm{~cm}$ and weighed $420 \mathrm{~g}$. On section, it was firm, solid, and yellowish. Microscopical sections (Fig. a to d) were typical of carcinoid tumour; there was a dense fibrous stroma infiltrated by mainly solid masses and strands of closely packed cells. The capsule, though infiltrated, was not perforated. The cells had uniform shape, size, and nuclei. Confirmatory evidence was obtained from the argentaffin reaction. Thorough search for teratomatous elements was negative. Nothing could be recognized of the ovarian structure.

The right Fallopian tube, left ovary and tube, uterus, appendix, and omentum were normal. The liver biopsy specimens did not show any carcinoid metastasis. The pleural fluid and the ascitic fluid did not show any malignant cells.

\section{Progress}

The postoperative course was smooth and there was no more flushing, erythema, and cyanosis as from the third day. All symptoms cleared in less than 2 weeks, including orthopnoea, lower limb oedema, and diarrhoea. Ascites did not recur.

Two and a half months after operation we performed right and left heart catheterization with coronary arteriography, and left and right ventricular angiograms. The haemodynamic data are indicated in the Table. A prominent ' $v$ ' wave in the right atrium, consistent with tricuspid regurgitation, and mild pulmonary stenosis were evident. Cine coronary arteriography showed moderate disease in the proximal anterior descending artery, just at the origin of a large diagonal branch, and some mild irregularities of the right coronary artery. 


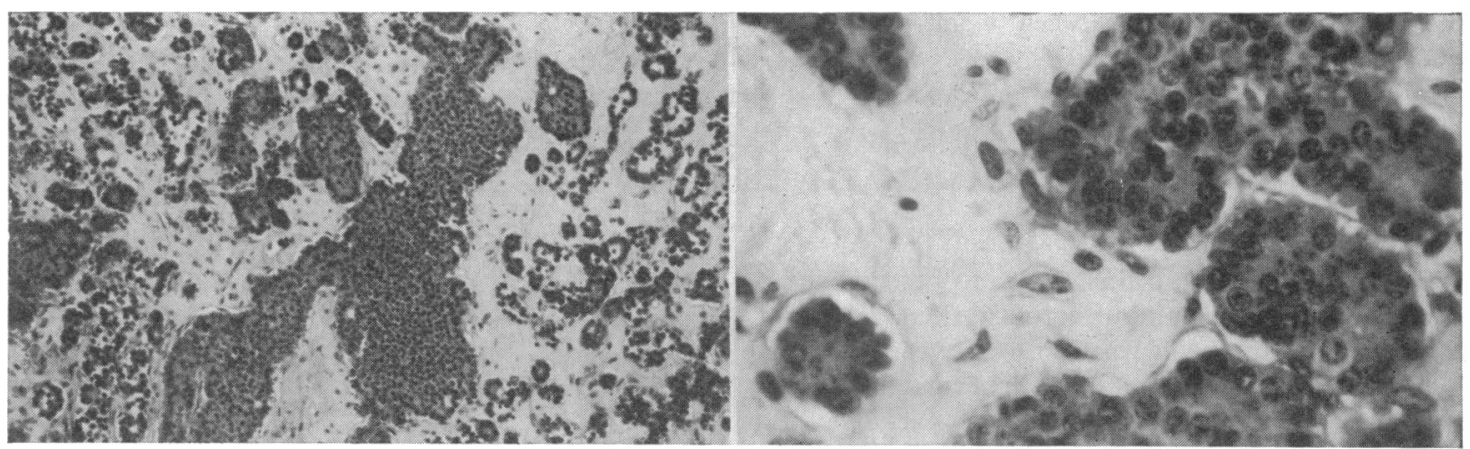

$a$

$b$

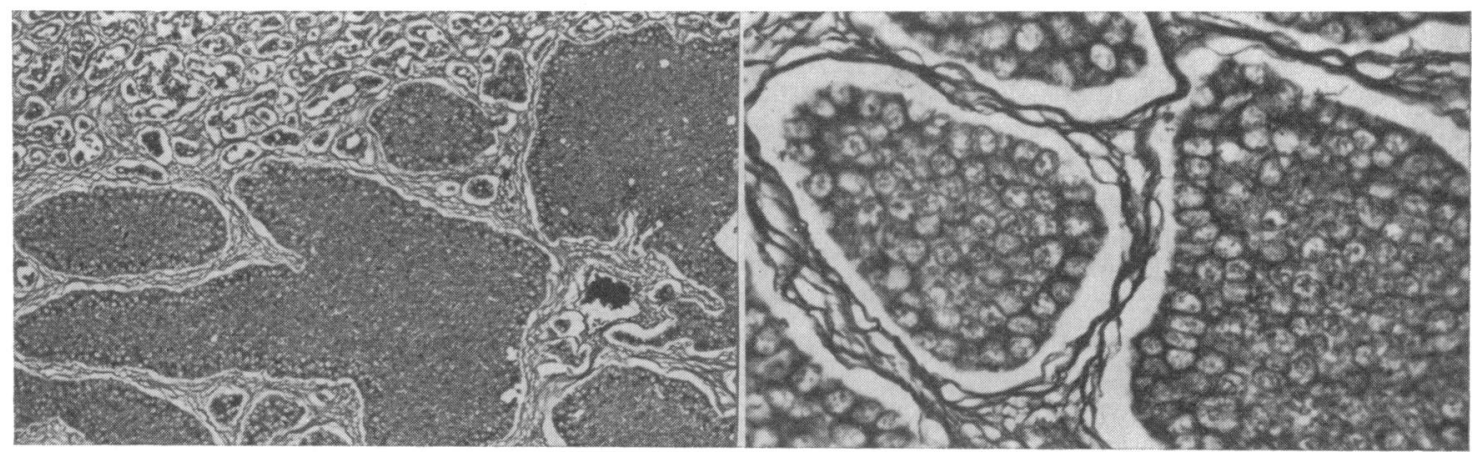

$c$

$d$

FI G. Microscopical sections showing ( $a$ and $b$ ) $a$ dense stroma infiltrated by carcinoid cells in various arrangements (Haematoxylin and eosin); ( $c$ and $d$ ) cytoplasmic argentaffin reaction with a curious annular perinuclear arrangement ( Gömöri stain). Magnifications are 80 for $a$ and $c, 335$ for $b$ and $d$.

\section{TABLE Haemodynamic data}

\begin{tabular}{|c|c|c|c|}
\hline \multirow{4}{*}{$\begin{array}{l}\text { Position } \\
\text { Pulmonary artery } \\
\text { Right ventricle } \\
\text { Right atrium }\end{array}$} & \multicolumn{2}{|c|}{ Pressure $(\mathrm{mmHg})$} & $\mathrm{O}_{2}$ Saturation (\%) \\
\hline & \multirow{2}{*}{\multicolumn{2}{|c|}{$\begin{array}{l}30 / 12 \\
45 / 16\end{array}$}} & \multirow{3}{*}{$\begin{array}{l}60 \\
60\end{array}$} \\
\hline & & & \\
\hline & & \\
\hline & v 24 & I6 & 60 \\
\hline Brachial artery & $142 / 85$ & 105 & \multirow{4}{*}{$\begin{array}{l}96 \\
96\end{array}$} \\
\hline Ascending aorta & $154 / 82$ & 105 & \\
\hline Left ventricle & \multirow{2}{*}{\multicolumn{2}{|c|}{$\begin{array}{l}\text { No diastolic } \\
\text { gradient }\end{array}$}} & \\
\hline $\begin{array}{l}\text { Left atrium to left } \\
\text { ventricle pullback }\end{array}$ & & & \\
\hline Left atrium & \multicolumn{2}{|r|}{ I4 } & 96 \\
\hline
\end{tabular}

Arterial-mixed venous $\mathrm{O}_{2}$ difference, $6 \cdot 1 \mathrm{ml} / \mathrm{roo} \mathrm{ml}$; cardiac output, $3.9 \mathrm{l} / \mathrm{min}$; cardiac index, $2.2 \mathrm{l} . / \mathrm{min}$ per $\mathrm{m}^{2}$; stroke index, $23 \mathrm{ml}$; systemic resistance, 20 units $(\mathrm{mmHg} / 1 . / \mathrm{min} /$ $\left.\mathrm{m}^{2}\right)$; pulmonary resistance, I unit $\left(\mathrm{mmHg} / 1 . / \mathrm{min} / \mathrm{m}^{2}\right)$; heart rate, $96 / \mathrm{min}$.
Cine angiocardiography showed left ventricular contractions to be within normal limits. No mitral stenosis or regurgitation were seen. The right ventricular contractions were moderately depressed with moderate increase in end-systolic and end-diastolic volumes. The right ventricle appeared to be enlarged and there was loss of the right ventricular trabeculations. There was severe tricuspid regurgitation seen from the first beat with an irregular tricuspid valve. No calcification was seen. The right atrium was large and about one and a half times the size of the right ventricle.

In November 1973, 13 months after operation, most of the physical signs related to the cardiac involvement had already disappeared. There remained a faint systolic murmur at the left sternal border which did not increase with respiration. Neck veins were no longer prominent and their pulsations appeared to be normal. The liver, about two finger-breadths below the costal margin, no longer pulsated. The electrocardiogram was unchanged. The heart size radiologically had decreased. She remained symptom free and 5-HIAA determination at 
monthly intervals ranged between 3 and $5 \mathrm{mg}$ in 24hour urine.

\section{Comments}

If the first spells of hot flushes are to be considered as indicative of the tumour activity, then the age of the tumour must be at least 13 to 14 years. Several gynaecological examinations had been done before and after menopause, the last two years ago. No ovarian mass had been felt, presumably because the tumour, though active, was too small to be palpated.

Bimanual compression of the ovarian mass vaginally provoked flushing, suggesting an ovarian carcinoid, though not necessarily primary. Such pressure on the tumour might also account for the flushing spells on straining during defaecation.

As usual in carcinoid heart disease, the cardiac findings in our patient consisted of enlargement of the right heart chambers with pulmonary and tricuspid valvar lesions. Pulmonary valve stenosis was not visualized in the cine angiocardiograms. The loss of the trabeculations of the right ventricle was presumably caused by the endocardial fibrosis, considered to be the main cardiac pathological feature of carcinoid heart disease.

We are grateful to Dr. Edgar M. Gedeon, Chairman of the Department of Pathology of the Central Public Health Laboratory, for the pathological study of our case; to Dr. Said Sayegh, cardiologist of the Berbir Medical Centre, who performed the haemodynamic and cine coronary angiocardiographic studies; to Dr. G. Scandar who operated on the patient; and to Dr. Robert Misk, senior gynaecologist at Baabda State Hospital, for his assistance and advice.

\section{References}

Acar, J., Auriol, M., Lainée, R., Hanania, G., Grimberg, F., El Hachimi, and Adam, Y. (1970). Cardiopathie carcinoïde et tumeur de l'ovaire. A propos d'un cas anatomoclinique. Annales de Médecine Interne (Paris), 121, 329.

Bancroft, J. H. J., O'Brien, D. J., and Tickner, A. (I964). Carcinoid syndrome due to carcinoid tumour of the ovary. British Medical fournal, 2, 1440.

Chatterjee, K., and Heather, J. C. (I968). Carcinoid heart disease from primary ovarian carcinoid tumors. A case report and review of the literature. American fournal of Medicine, 45, 643.

Ellis, J. D. (1965). Carcinoid syndrome resulting from a primary argentaffinoma of the ovary. Proceedings of the Royal Society of Medicine, 58, 237.

Haines, M. (197I). Carcinoid tumours of the ovary. Fournal of Obstetrics and Gynaecology of the British Commonwealth, 78, 1123.

Mouchet, A., Guivarc'h, M., and Voinchet, O. (1969). Les carcinoides primitifs de l'ovaire. fournal de Chirurgie, 97, 9.

Ruckes, J., and Stallkamp, B. (1967). Zur Morphologie und Genese des primären ovarialcarcinoids. Frankfurter Zeitschrift für Pathologie, 76, 235.

Stewart, M. J., Willis, R. A., and De Saram, G. S. W. (1939). Argentaffine carcinoma (carcinoid tumour) arising in ovarian teratomas. A report of two cases. Fournal of Pathology and Bacteriology, 49, 207.

Thorson, A., Biörck, G., Bjorkman, G., and Waldenström, J. (1954). Malignant carcinoid of the small intestine with metastases to the liver, valvular disease of the right side of the heart (pulmonary stenosis and tricuspid regurgitation without septal defects), peripheral vasomotor symptoms, bronchoconstriction and an unusual type of cyanosis. American Heart fournal, 47, 795.

Thorson, A., Hanson, A., Pernow, B., Söderström, N., Waldenström, J., Winblad, S., and Wulff, H. B. (1958). Carcinoid tumour within an ovarian teratoma in a patient with the carcinoid syndrome (carcinoidosis). Acta Medica Scandinavica, 16I, 495.

Torvik, A. (1960). Carcinoid syndrome in a primary tumour of the ovary. Acta Pathologica et Microbiologica Scandinavica, 48, $8 \mathrm{r}$.

Requests for reprints to Professor E. Stephan, Department of Clinical Medicine, French Faculty of Medicine, Beirut, Lebanon. 